\title{
Seasonal wind speed distribution analysis in west coast of Malaysia
}

\begin{abstract}
Wind in Malaysia varies according to the Northeast and Southwest monsoon. The transition period of the two monsoons, April and October inter-monsoon also influence the wind in Malaysia. The determination of the fit wind speed distribution has become a vital process in wind energy estimation and coastal engineering application. However, previous study focuses only on the fit annual distribution instead of the fit seasonal distribution of wind speed. The fit seasonal distribution of wind can leads to the proper installation of wind energy technology devices, the wind power generation and the pattern of the wind itself. Thus, this paper aims to determine the best fir distribution of monsoon and inter-monsoon occurred in Malaysia every year. The distribution that was tested is the Gamma, Log-normal and Weibull distribution model hence, the fit distribution was determined using Kolmogorov-Smirnov goodness-of-fit test. It was found that the Log-normal distribution fits best with all monsoon and inter-monsoon in Malaysia.
\end{abstract}

Keyword: Goodness of fit; Monsoon; Probability distribution; Seasonal distribution; Wind speed 